\section{BMJ Paediatrics Open}

\title{
Ethical dilemmas in providing acute medical care at home for children: a survey of health professionals
}

\author{
Penelope A Bryant (D) 1,2,3
}

\section{To cite: Bryant PA. Ethical dilemmas in providing acute medical care at home for children: a survey of health professionals. BMJ Paediatrics Open 2020;4:e000590. doi:10.1136/ bmjpo-2019-000590}

Received 9 0ctober 2019 Revised 18 January 2020 Accepted 21 January 2020

\section{Check for updates}

(C) Author(s) (or their employer(s)) 2020. Re-use permitted under CC BY-NC. No commercial re-use. See rights and permissions. Published by BMJ.

${ }^{1}$ Hospital-in-the-Home Department \& Infectious Diseases Unit, General Medicine The Royal Children's Hospital, Melbourne, Victoria, Australia ${ }^{2}$ Infection, Murdoch Children's Research Institute, Melbourne, Victoria, Australia ${ }^{3}$ Department of Paediatrics, University of Melbourne, Melbourne, Victoria, Australia

Correspondence to Dr Penelope A Bryant; penelope. bryant@rch.org.au

\section{ABSTRACT}

Objective Acute care at home is increasing. We aimed to determine the views of healthcare professionals on the ethics of providing home care and compare the impact of situational changes on their opinions.

Design An analysis of opinions of home healthcare professionals.

Setting The Australasian Hospital-in-the-Home Annual Conference, November 2017.

Participants Eighty physicians, nurses and allied health staff who provide acute care for children and adults at home.

Methods Clinical scenarios were presented about a 14 years old receiving intravenous antibiotics at home via an established home care pathway, and participants were asked to vote manually on whether providing home care was ethical.

Main outcomes The proportions of healthcare professionals who believed that provision of home care was ethical in different situations.

Results For each question the response rate ranged from $71 \%$ to $100 \%$. While the provision of acute home care was deemed ethical by the majority $(77 / 80,96 \%)$, this decreased when other factors were involved such as domestic violence (37/63 (59\%) OR $0.06,95 \% \mathrm{Cl} 0.02$ to $0.20, p<0.001)$ and parental reluctance $(28 / 67(42 \%)$ OR $0.02,95 \% \mathrm{Cl} 0.008$ to $0.09, \mathrm{p}<0.001)$. The age of consent affected the proportion who considered home care ethical against parental wishes: 16 years (48/58, 83\%) versus 14 years $(33 / 53,52 \%)$ OR $4.4,95 \% \mathrm{Cl} 1.9$ to $10.1, \mathrm{p}<0.001$. The lowest proportion to consider home care ethical (16\%) was when home care was deemed less than hospital care. Conclusions Home healthcare providers are supportive of the ethics of providing acute care at home for children, although differ among themselves with situational complexities. Applying the tenets of medical ethics (autonomy, non-maleficence, beneficence and justice) can provide insights into the factors that may influence opinions.

\section{INTRODUCTION}

Care at home for acute medical conditions is increasingly viewed and used as a viable alternative to hospital admission. ${ }^{12}$ The rationale applies to both patients and organisations. The majority of patients prefer to receive their care at home if possible, and have improved psychological outcomes and reduced risks

\section{What is known about the subject?}

Children are increasingly managed at home for treatment of acute conditions that would traditionally require hospital admission

- There is emerging evidence for the efficacy and safety of this approach, but a lack of discussion on the ethical aspects.

\section{What this study adds?}

Healthcare providers who are familiar with acute home care believe this care follows the ethical tenets of autonomy, beneficence, non-maleficence and justice.

- Ethical dilemmas arise when other people such as staff members and parents need to be considered.

- Provision of home care was felt to be least ethical when it was deemed inferior clinically to hospital care.

associated with admission such as hospitalacquired infections. ${ }^{3} 4$ For organisations, improved flow of patients and reduced costs make home care attractive. ${ }^{56}$ There is evidence in adults that safety and efficacy are comparable between home and hospital care in selected patients and conditions. ${ }^{7}$ While the evidence for safety and efficacy in acute conditions is scarcer in children, this too is accumulating. ${ }^{8-11}$ However, while there is some literature around the ethics of treating children with chronic conditions at home, ${ }^{12} 13$ the ethical aspects of treating children at home for acute conditions have not previously been explored.

Ethical behaviour has been considered in medicine since Hippocrates, and the International Code of Medical Ethics, ${ }^{14}$ or variants, have been adopted by many national medical associations. ${ }^{15-18}$ These are based on the four principles of medical ethics described by Beauchamp and Childress: autonomy, nonmaleficence, beneficence and justice. ${ }^{19}$ 
We aimed to understand the views of clinical professionals who provide home care on various ethical aspects of managing children with acute medical conditions at home that would otherwise necessitate hospital admission. Acute home programmes have names including hospital-in-the-home and medical home, whereby nursing, medical and allied health staff provide at least daily medical interventions in the home including intravenous antibiotics, acute wound dressings, chemotherapy and physiotherapy. We aimed to determine the ethical parameters within which home healthcare professionals believe they should be providing care to children at home.

\section{METHODS}

\section{Setting}

The Australasian Hospital-in-the-Home (HITH) Annual Conference November 2017.

\section{Participants}

Medical, nursing and allied health staff attendees to the conference, all of whom provide clinical services to patients at home.

\section{Design}

All attendees were invited to a session titled 'Ethical dilemmas in HITH practice'. The intention to survey opinions on ethical matters was explained and attendees were invited to leave the session if they wished, or stay and participate or not as they wished. Nobody left but four attendees declined to participate. Background was given on how ethical constructs can be used to explore practical dilemmas. A non-clinical scenario was given to show there is often no right answer, how ethical reasoning can be applied to either side of an argument and that increasing or changing available information can change how a situation is viewed ethically. It was explained that several questions would be asked for which there was no right answer and that the information they needed to make a fully informed decision may not be there. For each question, participants could choose to vote or not, and they were requested to hold up a blue sign if they thought the situation was ethical and a red one if they thought not. To try to mitigate any feeling of peer pressure to vote in a certain way, the signs were white on the back so the choice of response was only visible from the front with all participants facing forward. Two people counted votes and in case of discrepancy, a photograph was taken and attendees were assured these would be destroyed after verification. The session used a fictitious situation based on real dilemmas that arise in acute home care.

\section{Main outcomes}

The proportion of healthcare professionals who believed that provision of home care was ethical in different situations.

\section{Statistical analysis}

$\chi^{2}$ test was used to compare the proportion of responses to different situational questions, with ORs, $95 \%$ CIs and $\mathrm{p}<0.05$ considered significant.

\section{Patient and public involvement}

There were no patients or members of the public involved in any aspect of the study as it is an examination of opinions of clinical staff.

\section{RESULTS}

The participants at the Australasian HITH Society Annual Conference were predominantly from Australia and New Zealand and between the ages of 25 and 65 years. Their professional background was all in healthcare and all in home care, with 70\% nursing, 20\% allied health (predominantly physiotherapists) and $10 \%$ medical. A minority (5\%-10\%) were directly involved in paediatric home care. Two test questions ascertained the maximum number of voting participants and ensured an understanding of the process - the first aiming to elicit an 'ethical' response and the second a 'not ethical' response. Eighty out of 84 (95\%) attendees participated, all of whom voted 'ethical' for the first question and 'not ethical' for the second question. For the clinical scenario, after each piece of additional information, participants were asked to vote on 'Is it ethical to provide a home service for this patient in this situation?' Response rates for each question ranged from $71 \%$ to $100 \%$.

Question 1. A 14-year-old girl with cystic fibrosis (CF) needs a planned episode of care for an infective exacerbation. Your institution has a well-established home care pathway for ' $C F$ tune-ups' for adolescents with intravenous antibiotics and physiotherapy. You offer her this home care pathway or hospital care and she chooses home.

Home care was voted as ethical by a very high proportion of participants ( 77 votes, $96 \%$ ), all of whom work in home care and are therefore familiar with it (table 1).

Question 2. You discover that there is a history of domestic violence between adults in the household.

Compared with the previous response, the proportion $(37 / 63,59 \%)$ who thought providing a home service was ethical when domestic violence was involved was significantly decreased (OR $0.06,95 \%$ CI 0.02 to $0.20, \mathrm{p}<0.001)$.

Question 3A. You determine there is no current risk to nursing staff. However, the girl's mother tells you she is exhausted from chronic care of her child and was counting on hospital admission for respite.

3B. Her mother tells you if she doesn't get this respite, she will have to take unpaid leave and won't be able to afford to take everyone on a family holiday.

3C. Her mother tells you if she doesn't get this respite, she will have to take unpaid leave and won't be able to afford to buy a wheelchair for her other child who has a disability.

Compared with the first response, the proportion $(28 / 67,42 \%)$ who thought providing home care was ethical when the mother declared her reluctance due 
Table 1 Responses to ethical questions (see text for full questions)

\begin{tabular}{|c|c|c|c|}
\hline \multirow[b]{2}{*}{ Question } & \multirow[b]{2}{*}{$\begin{array}{l}\text { Responses } \\
\text { n (\%) }\end{array}$} & \multicolumn{2}{|c|}{ Vote results } \\
\hline & & $\begin{array}{l}\text { Ethical } \\
\text { n (\%) }\end{array}$ & $\begin{array}{l}\text { Not } \\
\text { ethical } \\
\text { n (\%) }\end{array}$ \\
\hline 1. Home treatment & $80(100)$ & $77(96)$ & $3(4)$ \\
\hline 2. Domestic violence & $63(79)$ & $37(59)$ & $26(41)$ \\
\hline \multicolumn{4}{|l|}{ 3. Parental respite } \\
\hline A. Maternal exhaustion & $67(84)$ & $28(42)$ & $39(58)$ \\
\hline B. Afford a family holiday & $57(71)$ & $28(49)$ & $29(51)$ \\
\hline C. Afford a wheelchair & $64(80)$ & $28(44)$ & $36(56)$ \\
\hline \multicolumn{4}{|l|}{ 4. Consent } \\
\hline A. 14 years old & $63(79)$ & $33(52)$ & $30(48)$ \\
\hline B. 16 years old & $58(73)$ & $48(83)$ & $10(17)$ \\
\hline $\begin{array}{l}\text { 5. Physiotherapy } \\
\text { unavailable }\end{array}$ & $61(76)$ & $10(16)$ & $51(84)$ \\
\hline 6. Bedroom sanctuary & $64(80)$ & $63(98)$ & $1(2)$ \\
\hline \multicolumn{4}{|l|}{ 7. Intramuscular injections } \\
\hline A. 1 day & $62(78)$ & $61(98)$ & $1(2)$ \\
\hline B. 2 days & $59(74)$ & $52(88)$ & 7 (12) \\
\hline C. 3 days & $60(75)$ & $31(52)$ & $29(48)$ \\
\hline
\end{tabular}

to exhaustion was significantly decreased (OR 0.02, $95 \%$ CI 0.008 to $0.09, \mathrm{p}<0.001)$. Different reasons for the respite request did not significantly affect the opinion on whether the care was ethical compared with maternal exhaustion: to afford a family holiday: $49 \%$ vs $42 \%$ (OR $1.3,95 \%$ CI 0.7 to $2.7, \mathrm{p}=0.3$ ), or to buy a wheelchair: $44 \%$ vs $42 \%$ (OR $1.1,95 \%$ CI 0.5 to $2.1, p=0.5$ ). Whether it was ethical to care for a child at home when the request for respite hospitalisation was to pay for a family holiday had the lowest response rate for all questions $(71 \%)$.

Question 4A. You are about to acquiesce to parental wishes, but the 14-year-old girl now insists that she wants to go home via HITH.

4B. What if the girl was 16 years old?

There was a significant difference with patient age (without any further information) about whether it was deemed ethical to provide home care per the patient's wishes against parental wishes: $48 / 58(83 \%)$ at 16 years versus $33 / 63(52 \%)$ at 14 years (OR $4.4,95 \%$ CI 1.9 to $10.1, \mathrm{p}<0.001)$.

Question 5. Everyone now agrees to proceed with treatment at home. However, the home care physiotherapist will be away during the treatment period, so the girl and her parents will need to do her physiotherapy.

Compared with the first response, the unavailability of physiotherapy led to the lowest proportion $(10 / 61,16 \%)$ of all questions of those who felt providing home care in this scenario was ethical (OR $0.008,95 \%$ CI 0.002 to 0.03 , $\mathrm{p}<0.001$ ).

Question 6. Your first visit to the home reveals a small apartment where the young girl's bedroom is her only sanctuary. This

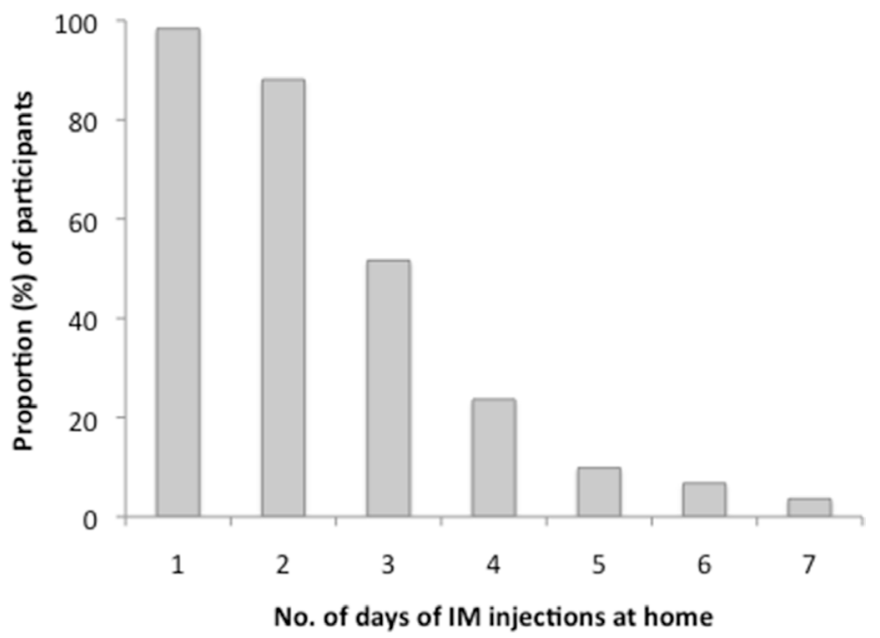

Figure 1 Proportion of participants who believe it is ethical to administer intramuscular injections at home by number of days.

is currently full of medical equipment to facilitate her being at home.

A high proportion of participants $(63 / 64,98 \%)$ voted that providing home care in this situation was ethical, with no difference from the original scenario (OR 2.5, $95 \%$ CI 0.2 to $24.1, \mathrm{p}=0.4$ ).

Question 7A. Towards the end of her HITH stay her peripherally inserted central catheter (PICC) blocks and you are unable to insert a cannula despite repeated attempts. The options are intramuscular injection or reinsertion of the PICC, for which she would need admission for a general anaesthetic. You decide to give an intramuscular injection so she can continue at home as she only needs one more day of parenteral antibiotics.

7B. Two days of intramuscular injections.

7C. Three days of intramuscular injections.

As the number of days of intramuscular injections at home in preference to admission for PICC replacement increased, the proportion of participants who felt this was ethical fell significantly (figure 1): 61/62 (98\%) vs 31/60 (52\%), OR $57,95 \%$ CI 7 to $439, \mathrm{p}<0.001$.

\section{DISCUSSION}

The application of ethical values to acute care for patients at home is a new area as home-based acute healthcare is in its relative infancy. The responses are those of health professionals who are all engaged in home healthcare, although predominantly in adults. The current model of care throughout Australia for paediatric acute noninpatient services is for nurses to visit the child's home to deliver care: hospital-in-the-home rather than, for example, outpatient infusion services. The questions were designed to test various aspects of the four tenets of medical ethics in this clinical environment.

Patient autonomy refers to respectful treatment of patients by ensuring disclosure of information and not constraining their right to make their own informed decision. This is exemplified in the first question where information is given to the patient and she decides between 
home care and hospital admission. The strong vote that this was ethical indicates that participants feel there is sufficient evidence that home care is effective and safe. Insufficient information is given to assess whether there was patient coercion, which is prohibited by the concept of autonomy, but on the face of it, the process appears ethical. The decision becomes less clear, as highlighted by the drop in 'ethical' votes, when the patient's mother's autonomy is included. This question also raised whether different reasons underpinning her autonomy (exhaustion, lack of funds) affect the ethical construct, but these were not viewed by participants as having as much impact as the mere fact of her opposing decision. In adult medicine, the patient's autonomy is paramount with the wishes of spouses and children being secondary. ${ }^{20}{ }^{21}$ In paediatrics, autonomy regarding medical care lies with those (usually the parent/s) holding parental rights, but the age at which the child's best interests are served by the child being autonomous is debated. More participants felt it was ethical for a 16 years old to provide consent than a 14 years old and this may reflect some lack of familiarity with the care of younger mature adolescents. The age at which a child can legally provide consent is different in different countries. In the UK, the test of 'Gillick competence' allows a minor under the legal age of consent (16 years) to be assessed as sufficiently mature to understand and make their own decisions and provide consent. This is in line with the ethical tenet of autonomy, which relies on competence. This medical case law has essentially been adopted in Australia and Canada, although only sporadically in the USA. Although adolescents in Australian and New Zealand hospitals are usually treated by paediatric/adolescent teams, the current limited reach of paediatric home care means that many adolescents at home are looked after by adult home care teams. The responses to this question raise the important issue of the need for adult home care providers to be upskilled in the specific ethical aspects of care needs for adolescents. However, even if consent is given by the adolescent, each home care service may have its own rules about whether an adult also needs to be present, which may supersede the ethical aspects of who ultimately provides consent.

Non-maleficence refers to the duty to avoid causing harm including pain, suffering and disablement. Beneficence refers to the duty to actively promote good for patients, to defend their rights and to remove conditions that will cause harm. Although they are sometimes seen as two sides of the same coin, one can obey the dictates of non-maleficence simply by refraining from acting, but beneficence requires positive action. Several questions highlighted these dual tenets, essentially creating an ethical dilemma, including provision of potentially invasive services in her place of sanctuary: beneficence of active care provision for her health, but non-maleficence requires not to the detriment to her psyche. However, as long as the patient is fully informed and has consented, autonomy dictates that we should not be paternalistic. Any detrimental effects may also differ between short episodes of acute care and ongoing chronic care where medical equipment might be a permanent fixture. The benefits and harms are also raised in the question on intramuscular injections, with increasing number (and therefore pain) correlating with decreasing acceptance. This adds a level of complexity when deciding on the ethical imperatives between the three options of home care, intramuscular injections and the small but serious potential harm of a general anaesthetic.

The issue of household domestic violence raises to whom the beneficence and non-maleficence need to be applied. In this situation there is an obligation of specific beneficence to the patient, and it potentially even increases the imperative for a professional to visit the home. However, the ethical balance shifted for nonresponders when non-maleficence needed to be considered for a staff member entering a potentially unsafe situation. Since there is a moral obligation to both, other aspects should be considered to guide decision-making such as the vulnerability of the individual and the risk of potential harm to either party, and for that more information is required. It is, however, worth stating that it is rare for domestic violence to be perpetrated against outsiders, and that the balance of most home healthcare providers is to provide the care and, if necessary, have two staff members visit together.

Finally, justice refers to how benefits and burdens should be distributed. It mandates the fair medical treatment of patients, with equal situations being treated equally, and unequal situations being treated in proportion to their inequalities. A large majority of participants felt it was not just to provide inferior treatment at home compared with what would be offered in hospital, reflecting the importance of physiotherapy in CF care. This is important because the concern around home care being inferior is a barrier to acute home care for many institutions and clinical staff. ${ }^{22}{ }^{23}$ Robust evidence that home care is as efficacious and safe as hospital care for children is increasing, but more is needed..$^{24}$ Of note, most home programmes only provide daily physiotherapy at home compared with twice daily in hospital, which is therefore already less, yet this is considered acceptable by respiratory physicians. The concept of 'good enough' has been discussed regarding parenting where perfection is not deemed necessary. It may be appropriate to apply the same concept to home services where the intensity of services is lower, but the quality must be as high. We did not explore how good would be considered 'good enough' (eg, physiotherapy via telehealth, a physiotherapist visiting alternate days) or compare this with the risks of inpatient admission. The other aspect is the balance of unequal situations. In a recent study of home intravenous antibiotic treatment for cellulitis, it was shown that parent and child quality of life was significantly higher at home and it cost three times less for the family than in hospital. ${ }^{2425}$ The efficacy level (the primary outcome) for non-inferiority was set lower for home than in hospital at the start of the $\operatorname{trial}^{26}$ because of the recognition of 
the benefits of home and acceptance of a proportionally lower level of efficacy, although efficacy was actually found to be higher at home. Unequal situations were tested in the question around maternal reasons for wanting her daughter to have a hospital admission. That the lowest response rate was recorded for whether saving for a family holiday was an ethical reason for not wanting home care may reflect the lack of paediatric healthcare professionals in the audience, as in paediatrics the child is considered within the holistic sphere of the family, and family well-being is considered an important component.

Study limitations are that it only evaluated opinions of those providing home services, and while a high proportion of participants engaged, it was a small survey. The majority predominantly provide care to adult patients, so would be less familiar with considering ethical aspects of paediatric care at home. The patient was chosen as an adolescent for this reason, but the answers around age of consent and parental respite may have been answered differently by hospital paediatricians and other healthcare providers. Additionally, because it was not completely anonymous (the technology was unavailable for electronic voting) people may have felt peer pressure to vote similarly. The mitigation for this was that the way which people voted (red or blue colour of vote) was only visible from the front and the participants were all facing forward. Additionally, the differences in proportions of votes for different questions suggest that this factor was not strong. One other limitation is that questions were limited to clinical dilemmas, and did not include other ethical dimensions to acute home care such as organisational issues (eg, rationing or payment of services ${ }^{27}$ ) and research.

The tenets of medical ethics do not aim to provide answers, or even guidelines, for managing moral issues; rather they provide a framework to identify and reflect on them. These results can provide a benchmark against which surveys of other groups regarding acute home care in children can be compared. The next important step will be to obtain the opinions of patients, families and other healthcare providers. The results show the relevance of considering ethical aspects of the provision of home care, both in building a service and in providing and constantly improving the quality of delivering acute medical care to children at home.

Acknowledgements Thanks to those who participated in the survey and to $\mathrm{Dr}$ Suzanne Boyce for counting.

Contributors PAB was the sole contributor on all aspects of the study and manuscript preparation and approval.

Funding The authors have not declared a specific grant for this research from any funding agency in the public, commercial or not-for-profit sectors.

Disclaimer PAB is in receipt of a Clinician Scientist Fellowship from the Murdoch Children's Research Institute, which had no role in any aspect of the study.

Competing interests None declared.

Patient consent for publication Not required.

Provenance and peer review Not commissioned; externally peer reviewed.
Data availability statement All data relevant to the study are included in the article or uploaded as supplementary information.

Open access This is an open access article distributed in accordance with the Creative Commons Attribution Non Commercial (CC BY-NC 4.0) license, which permits others to distribute, remix, adapt, build upon this work non-commercially, and license their derivative works on different terms, provided the original work is properly cited, appropriate credit is given, any changes made indicated, and the use is non-commercial. See: http://creativecommons.org/licenses/by-nc/4.0/.

ORCID iD

Penelope A Bryant http://orcid.org/0000-0002-5262-5323

\section{REFERENCES}

1 Bryant PA, Hopper SM. Alternatives to ward admission from the emergency department. J Paediatr Child Health 2016;52:237-40.

2 Sartain SA, Maxwell MJ, Todd PJ, et al. Users' views on hospital and home care for acute illness in childhood. Health Soc Care Community 2001;9:108-17.

3 Ibrahim LF, Hopper SM, Connell TG, et al. Evaluating an admission avoidance pathway for children in the emergency department: outpatient intravenous antibiotics for moderate/severe cellulitis. Emerg Med J 2017;34:780-5.

4 Strandvik B, Hjelte L, Malmborg AS, et al. Home intravenous antibiotic treatment of patients with cystic fibrosis. Acta Paediatr 1992;81:340-4.

5 Warner BW, Kulick RM, Stoops MM, et al. An evidenced-based clinical pathway for acute appendicitis decreases Hospital duration and cost. J Pediatr Surg 1998;33:1371-5.

6 Hensey C, Sett A, Connell T. Missed opportunites for outpatient parenteralantibiotic therapy for bacterial meningitis and pyelonephritis in children. Australasian Hospital-in-the-Home Society Annual Conference, Melbourne, 2014.

7 Caplan GA, Sulaiman NS, Mangin DA, et al. A meta-analysis of "hospital in the home". Med J Aust 2012;197:512-9.

8 Ibrahim LF, Hopper SM, Babl FE, et al. Who can have parenteral antibiotics at home?: a prospective observational study in children with moderate/severe cellulitis. Pediatr Infect Dis J 2016;35:269-74.

9 Raisch DW, Holdsworth MT, Winter SS, et al. Economic comparison of home-care-based versus hospital-based treatment of chemotherapy-induced febrile neutropenia in children. Value Health 2003;6:158-66.

10 Hodgson KA, Huynh J, Ibrahim LF, et al. The use, appropriateness and outcomes of outpatient parenteral antimicrobial therapy. Arch Dis Child 2016;101:886-93.

11 Scanlan BT, Ibrahim LF, Hopper SM, et al. Selected children with complicated acute urinary tract infection may be treated with outpatient parenteral antibiotic therapy at home directly from the emergency department. Pediatr Infect Dis J 2019;38:e20-5.

12 Manhas KP, Mitchell I. Children with complex care needs going home: the relevance of ethical ideas of proximity. Paediatr Child Health 2009;14:369-70.

13 Simonds AK. Respiratory support for the severely handicapped child with neuromuscular disease: ethics and practicality. Semin Respir Crit Care Med 2007;28:342-54.

14 Anon. World Medical association International Code of medical ethics: World Medical Association; 2006.

15 Anon. Code of ethics of the Canadian Medical association: Canadian Medical association; 1996.

16 Anon. American Medical Association Code of Medical Ethics updated 2016: American Medical Association; 2001.

17 Anon. Australian medical association code of ethics: Australian medical association; 2006.

18 Anon. Good medical practice: general medical Council UK; 2014.

19 Beauchamp TL, Childress J. Principles of biomedical ethics. New York: Oxford University Press, 2009.

20 Carrese JA. Refusal of care: patients' well-being and physicians' ethical obligations: "but doctor, I want to go home". JAMA 2006;296:691-5.

21 DeWolf Bosek MS, Cashman GS. Ethical obligations and concerns when trying to achieve a patient's wishes: ethics consultation. JONAS Healthc Law Ethics Regul 2008;10:76-7.

22 Nutting PA, Miller WL, Crabtree BF, et al. Initial lessons from the first national demonstration project on practice transformation to a patient-centered medical home. Ann Fam Med 2009;7:254-60.

23 Boyce SL, Ibrahim LF, Connell T. How many children who could be cared for at home are being missed and why? Australasian hospitalin-the-home Society annual conference, Melbourne, 2014. 
24 Ibrahim LF, Hopper SM, Orsini F, et al. Efficacy and safety of intravenous ceftriaxone at home versus intravenous flucloxacillin in hospital for children with cellulitis (choice): a single-centre, openlabel, randomised, controlled, non-inferiority trial. Lancet Infect Dis 2019;19:477-86.

25 Ibrahim LF, Huang L, Hopper SM, et al. Intravenous ceftriaxone at home versus intravenous flucloxacillin in hospital for children with cellulitis: a cost-effectiveness analysis. Lancet Infect Dis 2019:19:1101-8.

26 Ibrahim LF, Babl FE, Orsini F, et al. Cellulitis: home or inpatient in children from the emergency department (choice): protocol for a randomised controlled trial. BMJ Open 2016;6:e009606.

27 Wynia MK, Sabin JE. Ethical challenges come home. J Gen Intern Med 2013;28:9-11. 